\title{
Suckling and lactational anoestrus in wild gorillas (Gorilla gorilla)
}

\author{
K. J. Stewart \\ University of Cambridge, Sub-Department of Animal Behaviour, High Street, Madingley, \\ Cambridge CB3 8AA, U.K.
}

\begin{abstract}
Summary. The present observations of wild gorillas demonstrate that lactation has a major influence on birth spacing. The frequency of suckling declined as infants matured, from $>1 / \mathrm{h}$ during the first year to about $1 / 2 \mathrm{~h}$ by $30-36$ months when mothers usually resumed sexual cycling. In contrast, the length of suckling bouts remained relatively constant throughout lactation, averaging between 2.6 and $3.2 \mathrm{~min}$ per bout. Within infant age categories, suckling frequencies of $\leqslant 0.5$ bouts $/ \mathrm{h}$ were associated with mothers who had resumed cycling, whereas higher frequencies were associated with mothers who were still anoestrous. These results complement those obtained from studies of breast-feeding in humans, and support the suggestion that the frequency of suckling is a critical factor in the contraceptive effects of lactation.
\end{abstract}

Keywords: gorilla; lactational anoestrus; interbirth intervals; suckling frequency

\section{Introduction}

For most non-seasonally breeding mammals, lactational anovulation is a major determinant of birth spacing (Short, 1976, 1983; Altmann et al., 1978; Loudon et al., 1983). Although the precise mechanism is not fully understood, studies of breast-feeding in women show that suckling itself is the crucial stimulus in preventing ovulation (McNeilly \& McNeilly, 1979; Howie et al., 1982; Short, 1983; Gross \& Eastman, 1985). A key factor in the process appears to be the frequency of suckling bouts which will largely determine the length of the inter-bout interval. In women, suckling frequency correlates positively with the prolactin concentrations (a reliable indicator of amenorrhoea) and negatively with concentrations of gonadal hormones in the mother (Delvoye et al., 1977; Konner \& Worthman, 1980; Wood et al., 1985). In addition, suckling frequency is more closely related to maternal reproductive condition than are bout length or total time suckling (Konner \& Worthman, 1980).

Studies of lactation in traditional human societies that use neither contraception nor supplementary feeding have led to the conclusion that high suckling frequencies over an extended period are largely responsible for the long interbirth intervals of, for example, 44 months and 46 months among the !Kung and the Gainj respectively (Konner \& Worthman, 1980; Wood et al., 1985). However, it has been suggested that maternal nutrition has a greater influence on reproduction than does suckling, and indeed, it is generally found that poorly nourished women tend to have longer interbirth intervals than do well nourished women (Frisch, 1982, 1985; Ramachandran, 1985). There is, however, little evidence that body condition per se has a direct effect on interbirth intervals (Bongaarts, 1980, 1982; Lunn, 1985). Rather, it appears now that this influence may operate largely through the effects of body condition on suckling activity. Hungry mothers produce hungry babies who may have to suck more often and more vigorously to obtain sufficient nourishment (Huffmann et al., 1980; Delgado et al., 1982). This increased sucking frequency will in turn 
serve to suppress ovulation (Lunn, 1985). Similar conclusions were reached in a study of red deer (Loudon et al., 1983).

The mechanism of lactational anovulation may be a key to our understanding of variation in female fertility in primates and other mammals. However, data on how suckling activity relates to lactational anovulation comes almost entirely from studies of humans. Clearly, similar work on other species is needed, especially since interpretation of the human data is often difficult because of the many cultural influences on reproduction such as breast-feeding practices, access to infant formulae, use of contraception, or post-partum sex taboos (Ramachandran, 1985). The great apes have reproduction schedules similar to those of women (Harcourt et al., 1980; Tutin, 1980; Goodall, 1983), and hence may be particularly relevant for interspecific comparison (Short, 1980, 1983).

Data on suckling frequencies in wild apes exist only for chimpanzees (Goodall, 1968; Clark, 1977), although Fossey (1979) provided a qualitative description of weaning in wild gorillas. Furthermore, no studies on apes and very few on other primates (Nicolson, 1987; Lee, 1987) relate suckling frequencies to maternal reproduction. This paper therefore presents data from wild gorillas and considers (1) the influence of lactation on interbirth intervals, (2) the relationship between age of the infant and duration and frequency of suckling bouts and (3) the relationship between suckling bout frequency and reproductive state of the mother.

\section{Animals and Methods}

\section{Animals}

The subjects of this paper belong to a population of mountain gorillas (Gorilla gorilla beringei) living in the Virunga Volcanoes of Rwanda and Zaire. The data on demographic and reproductive parameters have been collected since 1967 as part of a long-term research programme of the Karisoke Research Center where this work was carried out. Details concerning various aspects of the demography, social structure, and mating system of these gorillas may be found in Harcourt et al. $(1980,1981)$ and Stewart \& Harcourt (1987).

The more detailed behavioural data on suckling were collected during field studies on social development of immature mountain gorillas. Field work was carried out during 8 and 6 months in 1974 and 1977, respectively, and during 22 months in 1981-1983. The subjects were immature animals up to 4 years of age (here referred to as 'infants') and their mothers. Since the study was primarily concerned with the social relationships that the immature animals formed as they gained independence from their mothers, offspring < 1 year of age were not sampled consistently and so there are very few data on frequencies of suckling for this age.

During each of the study periods, two social groups were observed. In 1974 and 1977, data came from 7 infants (4 males; 3 females) and 6 mothers; and in 1981-1983 from 7 infants ( 3 males; 4 females) and 7 mothers. These animals provided data on suckling frequencies and durations of suckling bouts. During 1981-1983, additional information on bout length only was provided by 1 male and 3 female infants born into one of the groups during the study period. The results exclude mother-offspring pairs in which the mother was pregnant.

\section{Recording techniques and analysis}

Behavioural data were recorded onto check sheets divided into 30 -sec intervals, with suckling bouts timed to the nearest $15 \mathrm{sec}$. All gorillas in the study groups were habituated to the presence of observers, but the degree of habituation changed from one study period to the next. In 1974 and 1977, individuals did not tolerate being followed consistently. This, combined with the very thick vegetation, precluded the use of focal animal sampling (Altmann, 1974). Therefore, a record was kept of when infants or their mothers moved into or out of sight by using 1-min instantaneous sampling, and the social interactions of any infants in sight were recorded. The number of suckling bouts per hour was then calculated by taking the mean of daily values for all days when an infant and/or its mother were in sight for more than $1 \mathrm{~h}$. Observations tended to be clumped between the hours of 10:00 and 16:00 h.

By 1981, the study groups were more habituated and data were collected using focal animal sampling plus ad-libitum recording of the occurrence of suckling bouts and their duration. Samples lasted $30 \mathrm{~min}$ each. No individual was sampled more than twice in a day, and there was a minimum of $2 \mathrm{~h}$ between focal samples on the same animal. The order of focal animals was determined before observations began. Samples for each individual were distributed as evenly as possible among six 2-h blocks between 06:00 and 18:00 h. However, observations in the two time blocks at either end of the day were under-represented. Monthly mean frequencies form the data base.

These techniques of data collection did not allow the interval between bouts of suckling to be measured. In considering the contraceptive effects of suckling, interbout interval might be a more reievant measure than suckling 
frequency (see Gross \& Eastman, 1985; Wood et al., 1985). However, the distinction is important only if suckling bouts are clumped in time. In gorillas, this was not the case, as the focal observations from 1981-1983 indicate. In the period from 08:00 to $16: 00 \mathrm{~h}$ during which $87 \%$ of observation time was concentrated, in neither study group was the distribution of observed bouts of suckling across the four 2-h blocks significantly different from the distribution of focal samples (G $=2 \cdot 1$, d.f. $=3, n=492$ focals, 118 bouts, $P>0.05$, for both groups). Therefore, mean frequency of suckling bouts is a reasonably accurate reflection of mean interbout interval in gorillas.

Although the recording methods and analyses differed between the early and later studies, both sets of values represent estimates of how often immature animals were suckled. There were no consistent differences between the two study periods for animals within age classes. Therefore, when presenting the data, I do not distinguish between the two periods. The sex of infants is also not distinguished, since small sample sizes within age classes made it impossible to detect sex differences. Finally, results from.the different social groups are combined because the number of infants in each group in each study period was so small.

The results represent values for daylight hours. All offspring spent the night in close body contact with their mothers. It is likely that they were suckled during this time, but whether rates differed from those during the day is not known.

\section{Statistics}

All statistical tests are from Siegel (1956) and are 2-tailed.

\section{Definitions}

Suckling bouts. Although it was not always possible to see an infant actually sucking, it was clear that nipple contact for purposes other than obtaining milk (e.g. for support when being carried) was rare. Therefore, a suckling bout was defined as a session of nipple contact of not less than $30 \mathrm{sec}$, separated by one whole minute with no nipple contact. Suckling for less than $30 \mathrm{sec}$ was extremely rare. Within bouts, offspring usually switched breasts at least once. Such switches were immediate and were ignored in the calculations of bout length as were all bouts for which the beginnings and ends were not observed.

Sexual cycling and conception. In wild gorillas, young nulliparous females had slight perineal swellings at the time of sexual activity, but in older parous females there were no visible morphological correlates of oestrus. Sexual cycling was therefore defined by the purely behavioural signs of proceptivity and copulation. Oestrous periods lasted only $2-3$ days and occurred at intervals of 28-30 days until conception, after which, sexual behaviour did occur, although intervals were more irregular (Stewart, 1977; Harcourt et al., 1980).

Pregnancy was difficult to detect throughout most of the 8.5-month gestation period (Ardito, 1976), and conception dates were determined by counting back 8.5 months from parturition. Because observers could be certain that a female had conceived only once she had given birth or the products of a miscarriage were found (the chances of which were slim), rates of conception and fetal death could not be calculated. Therefore, the interbirth intervals presented could in some cases have included more than one conception.

Nutritional independence. In a discussion of suckling, it is relevant to know the age at which infants become nutritionally independent. Mountain gorillas feed on relatively few plant species, but most foods involve some sort of preparation such as stripping leaves or removing outer stems (Fossey \& Harcourt, 1977; Watts, 1984). During their first year, infants ingest substantial amounts of plant material, but food preparation does not become common until after 12 months (Fossey, 1979). By 18-24 months, infants are probably nutritionally independent from their mothers. At this age, they spend about $25 \%$ of their time feeding, in contrast to $45-50 \%$ for subadults and adults (Harcourt \& Stewart, 1984). The youngest orphan observed in the study groups was estimated to be 14-20 months old (Fossey, 1979).

\section{Results}

\section{Interbirth intervals and lactational anoestrus}

Gorillas are not seasonal breeders and the overriding importance of lactation to birth spacing was obvious when infants died: the median interval between surviving offspring was 3.85 years or 46 months (22 intervals; 12 females), but intervals when unweaned infants died were significantly shorter (Mann-Whitney, $U=0, P<0.002$ ) with a median of 16.8 months ( 9 intervals; 6 females; this includes cases of infant survival up to 18 months). The median interval between the death of an infant and the birth of the next was 12 months ( $N=9$ intervals; 6 females). Subtracting 8.5 months for gestation (Ardito, 1976) gives a median period of 3.5 months from the complete cessation of suckling to next conception. 
For 8 females for which there are data, the median interval from parturition to first observed post-partum oestrus was 3 years or 36 months (range $=2 \cdot 2-3 \cdot 9$ years). This agrees well with the duration of lactational anoestrus that was calculated using the median interbirth interval. Thus, subtracting 8.5 months for gestation plus 3.5 months for conception from the median birth interval of 46 months gives a median duration of 34 months for lactational anoestrus.

\section{Duration of lactational anoestrus and subsequent reproduction}

An early return of post-partum sexual cycling does not necessarily mean more rapid reproduction (Altmann et al., 1978). However, what few data exist for gorillas suggest that mothers who return to cycling early might in fact conceive early as well. Of 7 females for which there is enough information, those which resumed post-partum cycling before the overall median of 34 months tended to have shorter birth intervals (mean $=3.7$ years or 44.4 months; $N=4$ ) than did those who first cycled after 34 months (mean $=5.4$ years or 64.8 months; $N=3$ ), although the difference was not signficant (Mann-Whitney, $U=1, P=0 \cdot 14$ ).

\section{Suckling and age of offspring}

Figure 1 presents data on changes in suckling frequency and durations of suckling bouts as infants matured and shows that the two measures differed markedly in how they changed over time. Suckling frequency decreased with age of offspring $\left(r_{\mathrm{s}}=-0.964, P<0.02\right)$ the drop being sharpest during the first 24 months. Between 30 and 36 months, when females normally resumed cycling (see above), frequencies averaged about once every $2 \mathrm{~h}$ (Fig. 1a). In contrast, the duration of individual suckling bouts changed very little during maturation, averaging between 2.6 and 3.2 min (Fig. 1b). The mean duration of suckling bouts for 8 infants of less than 6 months was very similar, at $3 \mathrm{~min}$ for the median infant.

\section{Suckling and reproductive state of mother}

Table 1 shows the relation between the frequency of suckling and mothers' reproductive state for offspring of similar ages. Because there were insufficient data per month from 1974 and 1977 , only data from 1981-1983 were used in the analysis. The observations on each infant were divided into 4-month blocks with not less than 10 focal samples per block, and a mean suckling frequency for each age block was calculated. The data were then separated according to whether or not the mother had cycled (been observed to copulate) during that time period. For one female which was not observed in oestrus before she conceived, the time of first post-partum oestrus was estimated by counting back 3.5 months from her conception date (see above).

Considering only those age groups that included mothers in both reproductive states (i.e. $>24-40$ months) the results indicate that, for similarly-aged infants, suckling frequencies tended to be lower if mothers were cycling than if they were not. The data suggest that suckling frequencies at or below about 0.5 bouts/h were associated with a mother's return to sexual cycling.

Suckling after the first month or so of pregnancy was rare. Of 7 offspring for which there are data, the median animal was never observed to be suckled beyond 1 month after its mother conceived (range $=0-4$ months).

\section{Discussion}

The results from wild gorillas support the idea that the frequency of suckling is an important factor in lactational anovulation, which itself is a major determinant of birth spacing. Firstly, the frequency of suckling bouts declined as infants matured, whereas the duration of bouts remained fairly constant throughout the period of lactation. Secondly, for infants of a given age, relatively 

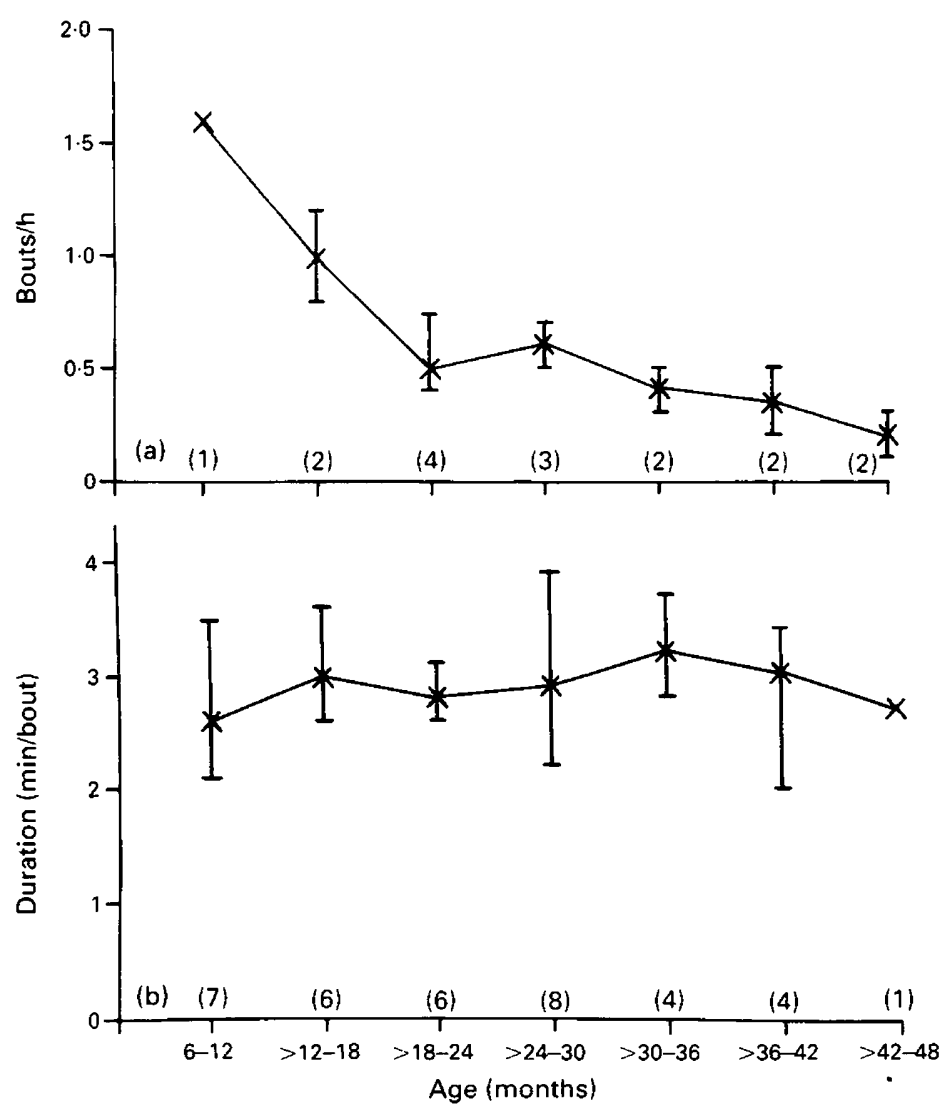

Fig. 1. Frequency (a) and duration (b) of suckling in bouts in relation to offspring age. The mean (x) and range (bar) of individuals' mean frequencies (a) and mean bout length (b) are shown for each age category. (N) number of infants per age interval. In (a), values for 1974 and 1977 periods are based on a median of 11 observation days per individual (range $=8-33$ ), and from 1981-1983, on a median of 43 focal samples per individual value (range $=29-72$ ). In (b) the median number of suckling bouts per individual was 4 (range $=1-23$ ). See 'Methods' for more detail.

low suckling frequencies were associated with mothers that had resumed sexual cycling, whereas higher frequencies were associated with mothers that were still anoestrous. The results suggest that there may be a critical frequency of around one bout every $2 \mathrm{~h}$, above which lactational anovulation is maintained and below which mothers are more likely to resume sexual cycling. Although these data do not prove a causal link between the frequency of suckling and post-partum anovulation, they support results from studies of humans in which changes in suckling activity were directly related to changes in maternal hormone concentrations (see 'Introduction').

Some of the data from gorillas are remarkably similar to those obtained from work in traditional human societies that use neither contraception nor supplementary feeding. For example, among the Gainj of Papua New Guinea, suckling episodes occurred about twice an hour in very young infants and declined to once per hour in 3-year-olds, while the duration of suckling bouts averaged $3.3 \mathrm{~min}$ per bout throughout the breast-feeding period. Prolactin concentrations in the mother declined in exact parallel with suckling frequency during maturation (Wood et al., 1985). 
Table 1. Mean number of suckling bouts per hour (based on a minimum of 10 focal samples per individual per age group) for infants in different age classes according to mothers' reproductive state

\begin{tabular}{lcccccc}
\hline & \multicolumn{6}{c}{ Age of infants (months) } \\
\cline { 2 - 7 } Infants & $>20.24$ & $>24-28$ & $>28-32$ & $>32-36$ & $>36-40$ & $>40-44$ \\
\hline $\mathrm{Mg}$ & 0.9 & 0.9 & 0.9 & 0.6 & & \\
$\mathrm{Tx}$ & 0.6 & $0.3^{*}$ & $0.5^{*}$ & & & \\
$\mathrm{Bp}$ & 0.4 & $0.4^{*}$ & $0.3^{*}$ & & & \\
$\mathrm{Jz}$ & 0.9 & 0.6 & & & & \\
$\mathrm{Dy}$ & & 0.6 & $0.5^{*}$ & $0.5^{*}$ & 0.8 & $0.4^{*}$ \\
$\mathrm{Ca}$ & & & & 0.3 & $0.8 *$ & \\
$\mathrm{Su}$ & & & & $0.3^{*}$ & $0.4^{*}$ & \\
Mean & 0.7 & 0.7 & 0.9 & 0.45 & 0.8 & \multirow{2}{*}{$0.4^{*}$} \\
& & $0.35^{*}$ & $0.4^{*}$ & $0.4^{*}$ & $0.4^{*}$ & 0 \\
\hline
\end{tabular}

Asterisks indicate values for infants whose mothers had resumed sexual cycling during that time block.

The data from other primates on suckling frequencies are sparse, but those available show that, as for gorillas and humans, the frequency of suckling bouts declines as infants mature, while the duration of bouts changes little (wild chimpanzees, Pan trogolodytes: Clark, 1977; wild baboons, Papio anubis: Nicolson, 1987). In addition, a relation between suckling activity and subsequent reproduction was shown in a study of olive baboons (Papio anubis) in which relatively frequent daily suckling was correlated with a relatively long period of post-partum anoestrus (Nicolson, 1987). In non-primates too, even in a highly seasonal mammal like the red deer, the frequency of suckling has been related to a mother's likelihood of conceiving in the next breeding season (Loudon et al., 1983).

There were too few data on gorillas to consider the causes of variation in suckling frequencies among females with infants of similar ages. In other primates, female reproduction appears to be influenced by a variety of factors that might operate through their effects on suckling frequency. These factors include age, parity, and dominance rank of the mother (Altmann, 1980; Harcourt, 1987; Nicolson, 1987), sex of the infant (Simpson et al., 1981), and, as in humans (see 'Introduction'), food availability or nutritional state (Sugiyama \& Ohsawa, 1982; Whitten, 1983; Lee, 1987). Suckling activity may be altered through effects on the infants' behaviour (e.g. suckling demands), or mothers' behaviour (e.g. restricting access to her nipples) or both. For example, in vervet monkeys, mothers living in a rich habitat with abundant food conceived sooner than did those in a poorer area. This was related to the relatively early age at which the better nourished mothers began weaning their infants, and a subsequent early return to sexual cycling (Lee, 1987).

Clearly more studies are needed to understand fully not only the mechanism of lactational anovulation but also the ways in which mothers and infants interact to produce a given level of suckling, and the various life history, social and ecological factors that might affect this. These issues are relevant to questions concerned with variation in female fertility, including theoretical issues such as the evolution of parental investment strategies (Trivers, 1972; Clutton-Brock et al., 1982). Especially useful would be work on various species that, like the human studies, measured suckling while monitoring maternal hormone concentrations (e.g. Short, 1984). In most species, the relationship between suckling activity and reproduction has not been investigated in any detail. Since in humans an understanding of lactation's contraceptive effects has contributed to studies of nutrition, demography, and reproduction (e.g. Knodel, 1977; Lunn, 1985), complementary work on other species is needed. 
I thank the governments of Rwanda and Zaire for permission to work in their countries; the Office Rwandais du Tourisme et des Parc Nationaux and the Institute Zairois pour la conservation de la Nature for authorization to study in their National Parks; the Harry Frank Guggenheim Foundation and National Geographic Society for funding upkeep of the Karisoke Research Center where this work was carried out; Sandy Harcourt, Robert Hinde, Phyllis Lee, and Roger Short for criticism of the manuscript: Roger Short for his encouragement and enthusiasm; and Sandy Harcourt for invaluable help and advice at all stages of this work.

\section{References}

Altmann, J. (1974) Observational study of behavior: sampling methods. Behaviour 49, 227-267.

Altmann, J. (1980) Baboon Mothers and Infants. Harvard University Press, Cambridge.

Altmann, J., Altmann, S. \& Hausfater, G. (1978) Primate infant's effects on mother's future reproduction. Science, N.Y. 201, 1028-1030.

Ardito, G. (1976) Check-list of the data on the gestation length of primates. J. hum. Evol. 5, 213-222.

Bongaarts, J. (1980) Does malnutrition affect fecundity? A summary of evidence. Science, N.Y. 208, 564-569.

Bongaarts, J. (1982) Malnutrition and fertility. Science, N.Y. 215, 1273-1274.

Clark, C.B. (1977) A preliminary report on weaning among chimpanzees of the Gombe National Park, Tanzania. In Primate Bio-Social Development, pp. 235-260. Eds S. Chevalier-Skolnikoff \& F. Poirer. Garland Publishing Inc., London.

Clutton-Brock, T.H., Guinness, F.E. \& Albon, S.D. (1982) Red Deer. Behaviour and Ecology of Two Sexes. Edinburgh University Press, Edinburgh.

Delgado, M.L., Martorell, R. \& Klein, R.E. (1982) Nutrition, lactation and birth interval components in rural Guatemala. Am. J. clin. Nutrition 35, 1468-1476.

Delvoye, P., Demaegd, M., Delogne-Desnock, J, \& Robyn, C. (1977) The influence of the frequency of nursing and of previous lactation experience on serum prolactin in lactating mothers. J. biosoc. Sci. 9 , $447-451$.

Fossey, D. (1979) Development of the mountain gorilla (Gorilla gorilla beringei) through the first thirty-six months. In The Behavior of the Great Apes, pp. 138184. Eds D. A. Hamburg \& E. R. McCown. Benjamin/Cummings Publ. Co., Menlo Park.

Fossey, D. \& Harcourt, A.H. (1977) Feeding ecology of free-ranging mountain gorilla (Gorilla gorilla beringei). In Primate Ecology, pp. 415-447. Ed. T. H. Clutton-Brock. Academic Press, London.

Frisch, R.E. (1982) Malnutrition and fertility. Science, N.Y. 215, 1272-1273.

Frisch, R.E. (1985) Maternal nutrition and lactational amenorrhoea: perceiving the metabolic costs. In Maternal Nutrition and Lactational Infertility, pp. 65-79. Ed. J. Dobbing. Raven Press, New York.

Goodall, J. van Lawick (1968) The behaviour of freeliving chimpanzees in the Gombe Stream Reserve. Anim. Behav. Monogr. 1, 161-311.

Goodall, J. (1983) Population dynamics during a 15 year period in one community of free-living chimpanzees in the Gombe National Park, Tanzania. Z. Tierpsychol. 61, 1-60.

Gross, B.A. \& Eastman, C.J. (1985) Prolactin and the return of ovulation in breast-feeding women. $J$. biosoc. Sci., Suppl. 9, 25-42.

Harcourt, A.H. (1987) Dominance and fertility among female primates. J. Zool., Lond. 213, 471-487.

Harcourt, A.H. \& Stewart, K.J. (1984) Gorillas' time feeding: aspects of methodology, body size, competition and diet. Afr. J. Ecol. 22, 207-215.

Harcourt, A.H., Fossey, D., Stewart, K.J. \& Watts, D.P. (1980) Reproduction in wild gorillas and some comparisons with chimpanzees. J. Reprod. Fert., Suppl. 28, 59-70.

Harcourt, A.H., Fossey, D. \& Sabater Pi, J. (1981) Demography of Gorilla gorilla. J. Zool., Lond. 195, 215-233.

Howie, P.W., McNeilly, A.S., Houston, M.J., Cook, A. \& Boyle, H. (1982) Fertility after childbirth: postpartum ovulation and menstruation in bottle and breast feeding mothers. Clin. Endocr. 17, 323-332.

Hufimann, S.L., Chowdhury, A.K.M.A., Chakraborty, J. \& Simpson, N.K. (1980) Breast feeding pattern in rural Bangladesh. Am. J. clin. Nutr. 33, 144-154.

Knodel, J. (1977) Breast-feeding and population growth. Science, N.Y. 198, 1111-1115.

Konner, M. \& Worthman, C. (1980) Nursing frequency, gonadal function, and birth spacing among !Kung hunter-gatherers. Science, N.Y. 207, 788-791.

Lee, P.C. (1987) Nutrition, fertility and maternal investment in primates. J. Zool., Lond. 213, 409-422.

Loudon, A.S.I., McNeilly, A.S. \& Milne, J.A. (1983) Nutrition and lactational control of fertility in red deer. Nature, Lond. 302, 145-147.

Lunn, P.G. (1985) Maternal nutrition and lactational infertility: the baby in the driving seat. In Maternal Nutrition and Lactational Infertility, pp. 41-53. Ed. J. Dobbing. Raven Press, New York.

McNeilly, A.S. \& McNeilly, J.R. (1979) Effects of lactation on fertility. Br. med. Bull. 35, 151-154.

Nicolson, N.A. (1987) Infants, mothers, and other females. In Primate Societies, pp. 330 -342. Eds B. B. Smuts, D. L. Cheney, R. M. Seyfarth, R. W. Wrangham \& T. T. Struhsaker. Uniyersity of Chicago Press, Chicago.

Ramachandran, P. (1985) Maternal nutrition and lactational infertility: a review. In Maternal Nutrition and Lactational Infertility, pp. 93-108. Ed J. Dobbing. Raven Press, New York. 
Short, R.V. (1976) The evolution of human reproduction. Proc. R. Soc. B 195, 3-24.

Short, R.V. (1980) The great apes of Africa. J. Reprod. Fert., Suppl. 28, 3-11.

Short, R.V. (1983) The biological basis for the contraceptive effects of breast feeding. In Advances in International Maternal and Child Health, vol. 3, pp. 27-39. Eds D. B. Jelliffe \& E. F. P. Jelliffe. Oxford University Press, London.

Short, R.V. (1984) Breast feeding. Sci. Amer. 250, 35-41.

Siegel, S. (1956) Nonparametric Statistics for the Behavioral Sciences. McGraw-Hill, New York.

Simpson, M.J.A., Hooley, J. \& Zunz, M. (1981) Infantrelated influences on birth intervals in rhesus monkeys. Nature, Lond. 290, 49-51.

Stewart, K.J. (1977) The birth of a wild mountain gorilla (Gorilla gorilla beringei). Primates 18, 965-976.

Stewart, K.J. \& Harcourt, A.H. (1987) Gorillas: variation in female relationships. In Primate Societies, pp. 155-164. Eds B. B. Smuts, D. L. Cheney, R. M. Seyfarth, R. W. Wrangham \& T. T. Struhsaker. University of Chicago Press, Chicago.
Sugiyama, Y. \& Ohsawa, H. (1982) Population dynamics of Japanese monkeys with special reference to the effect of artificial feeding. Folia primatol. 39, 238-263.

Trivers, R.L. (1972) Parental investment and sexual selection. In Sexual Selection and the Descent of Man, pp. 136-179. Ed. B. Campbell. Heinemann, London.

Tutin, C.E.G. (1980) Reproductive behaviour of wild chimpanzees in the Gombe National Park, Tanzania. J. Reprod. Fert., Suppl. 28, 43-57.

Watts, D.P. (1984) Composition and variability of mountain gorilla diets in the central Virungas. Am.J. Primatol. 7, 323-356.

Whitten, P.L. (1983) Diet and dominance among female vervet monkeys (Cercopithecus aethiops). Am. J. Primatol. 5, 139-159.

Wood, J.W., Lai, D., Johnson, P.L., Campbell, K.L. \& Maslar, I.A. (1985) Lactation and birth spacing in Highland New Guinea. J. biosoc. sci., Suppl. 9, 159-173.

Received 30 September 1987 